\title{
Optimization of Microstrip Patch Antenna on C Band and X Band with Radome Effect
}

\author{
Mayank Bhargava \\ MTech student \\ NIIST, Bhopal
}

\author{
Anubhuti Khare \\ UIT RGPV Bhopal
}

\author{
Rajesh Nema \\ Asst Professor \\ NIIST, Bhopal
}

\begin{abstract}
Microstrip patch antenna is versatile and vast field of antenna theory. A particular aspect of work done in this field is presented. In addition a different antenna configuration that improve electrical performance and sustainability is described. We analyzed microstrip antenna in IE3D by finite moment of method. The proposed antenna designs have been analyzed between $1 \mathrm{GHz}$ to $20 \mathrm{GHz}$. When the proposed antenna design of different geometries (i.e. Rectangular, Triangular and Circular) were examined for the two dielectrics i.e. RT duroid 5870 with dielectric constant 2.33, loss tangent 0.0005 and Ferro A6M, LTCC with dielectric constant 5.9, loss tangent 0.0012 the results are : For rectangular geometry return losses $=-22 \mathrm{~dB}$, VSWR $=1.238$, $\mathrm{Z}=60.83 \Omega$ at $6 \mathrm{GHz}$; For triangular geometry return losses $=$ $-12.2 \mathrm{~dB}, \mathrm{VSWR}=1.648, \mathrm{Z}=78.35 \Omega$ at $10 \mathrm{GHz}$, For circular geometry return losses $=-15.5 \mathrm{~dB}, \mathrm{VSWR}=1.409, \mathrm{Z}$ $=36.65 \Omega$ at $10 \mathrm{GHz}$.
\end{abstract}

\section{General Terms}

Rectangular microstrip patch antenna, Triangular patch antenna, Circular patch antenna.

\section{Keywords}

Microstrip antenna, IE3D Simulator, Dielectric substrate, Losses.

\section{INTRODUCTION}

Different geometries of patch antenna have been investigated by the researchers. In those studies, they have not employed any dielectric substrate in the form of radome above the patch. This radome protects the patch from environmental losses and uplifts the antenna performance. Triangular patch with radome is least investigated geometry. In this paper we have analyzed all the three geometries and tried to find out at which feed point geometries will give better return loss. For our detected feed point, we have checked out all remaining parameters for it such as $\mathrm{dB}$ and phase of $\mathrm{S}$ parameter, magnitude and phase of $\mathrm{Y}$ parameter, magnitude and phase of $\mathrm{Z}$ for $\mathrm{S}$ parameter, magnitude and phase of $\mathrm{Z}$ parameter, real and imaginary part of $\mathrm{Y}$ parameter, real and imaginary part of Z, Smith chart and VSWR.

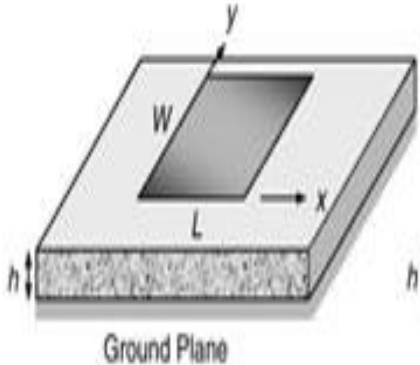

(a)

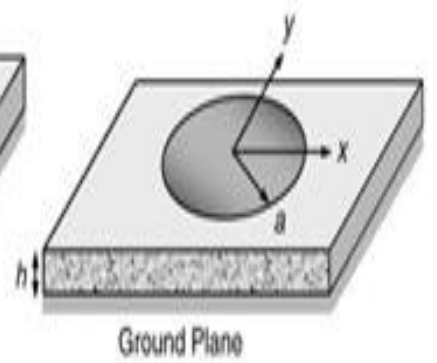

(b) (a) Rectangular micro strip patch antenna (b) Circular micro strip patch antenna

\section{EFFECTIVE PARAMETER}

Radomes, also known as RADAR domes, are protective dielectric coverings or a dielectric shells that encloses an antenna. The principal purpose of a radome is to shield the antenna and associated equipment from the environment. This improves system availability since the antenna is not affected by winds, rain, or ice. Typical applications include antennas for radar, telemetry, tracking, cellular communications, surveillance, and radio astronomy.

A dielectric or ferrite coating on the surface of an antenna can alter the electromagnetic characterstic, provide electrical insulation and protect the antenna from environment. Some ferrite and dielectric ceramic coatings can allow certain antenna designs to be reduced in size or height while providing acceptable radiation characteristic.

\section{PROPOSED ANTENNA DESIGN}

(a) For Rectangular Geometry

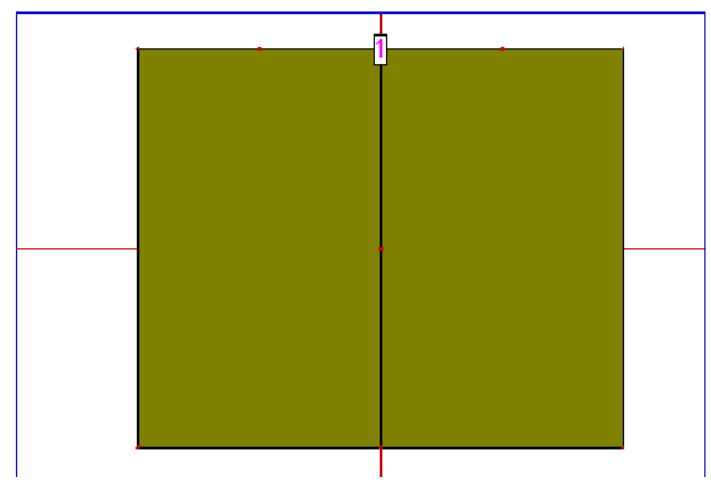

(b) For Triangular Geometry 


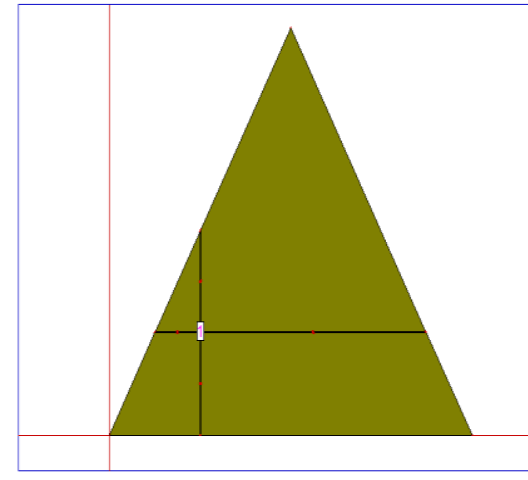

(c) For Circular Geometry

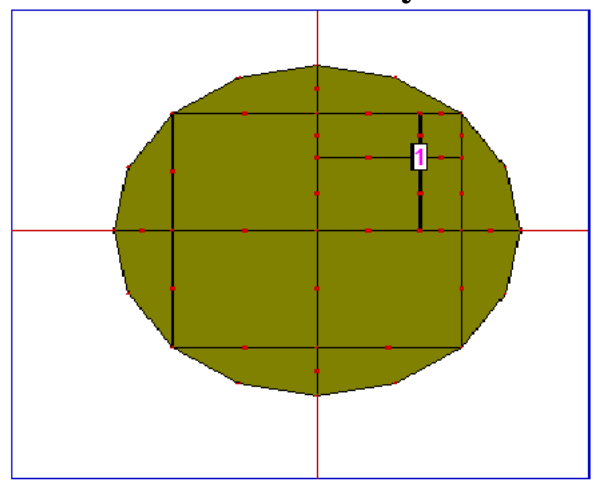

4. SIMULATED MICROSTRIP RECTANGULAR PATCH ANTENNA IN IE3D SIMULATOR FOR RT DUROID 5870 AND FERRO A6M, LTCC CONSIDERING RADOME EFFECT

(1) VSWR VS FREQUENCY (IN GHZ)

\section{(a) For Rectangular Geometry}

VSWR IS EFFECTIVE AND MINIMUM BETWEEN 1 TO $10 \mathrm{GH}_{\mathrm{Z}}$

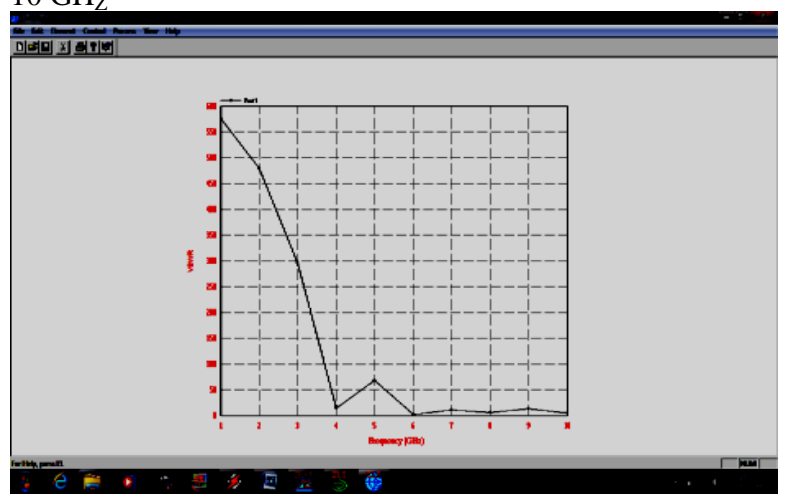

For proposed design the value of VSWR is effective between $1 \mathrm{GHz}$ to $10 \mathrm{GHz}$, for this value return loss is minimum. At $6 \mathrm{GHz}$ return loss is $-22 \mathrm{~dB}$ and VSWR is 1.238 , which is minimum value.

\section{(b) For Triangular Geometry}

VSWR IS EFFECTIVE AND MINIMUM BETWEEN 1GHz TO $15 \mathrm{GHz}$

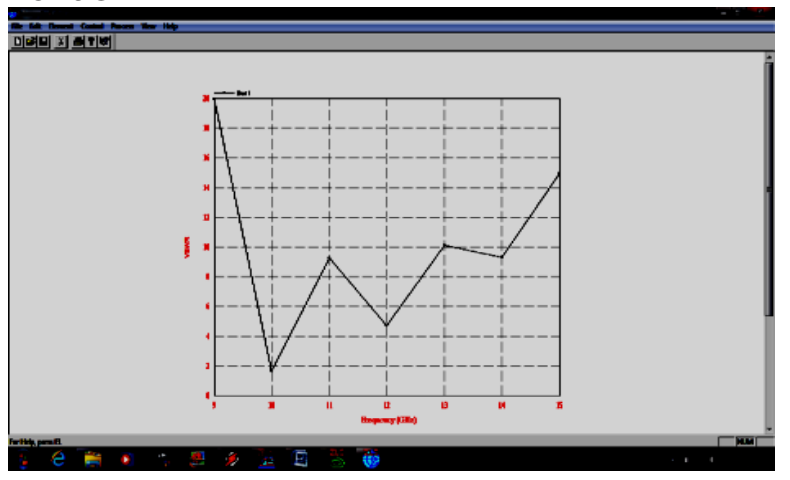

For the proposed design the value of VSWR is effective between $1 \mathrm{GHz}$ to $15 \mathrm{GHz}$, for this value the value of return loss is mimimum. At $10 \mathrm{GHz}$ the value of return loss is $12.2 \mathrm{~dB}$ at $10 \mathrm{GHz}$ and VSWR is 1.648 , which is minimum for this geometry.

\section{(d) For Circular Geometry}

VSWR IS EFFECTIVE AND MINIMUM BETWEEN 1 TO $15 \mathrm{GHz}$

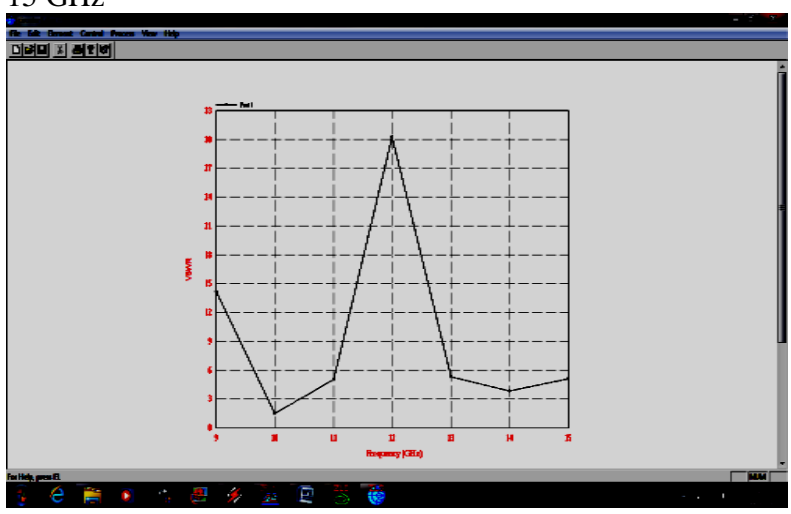

For proposed design the value of VSWR is effective between $1 \mathrm{GHz}$ to $15 \mathrm{GHz}$, for this value return loss is minimum. At $10 \mathrm{GHz}$ return loss is $-15.5 \mathrm{~dB}$ and VSWR is 1.4089 , which is minimum value.

\section{(2) RETURN LOSS VS FREQUENCY (IN $\mathrm{GHz})$}

\section{(a) For Rectangular Geometry}

At frequency of $6 \mathrm{GHz}$ the value of return loss is $-22 \mathrm{~dB}$. 


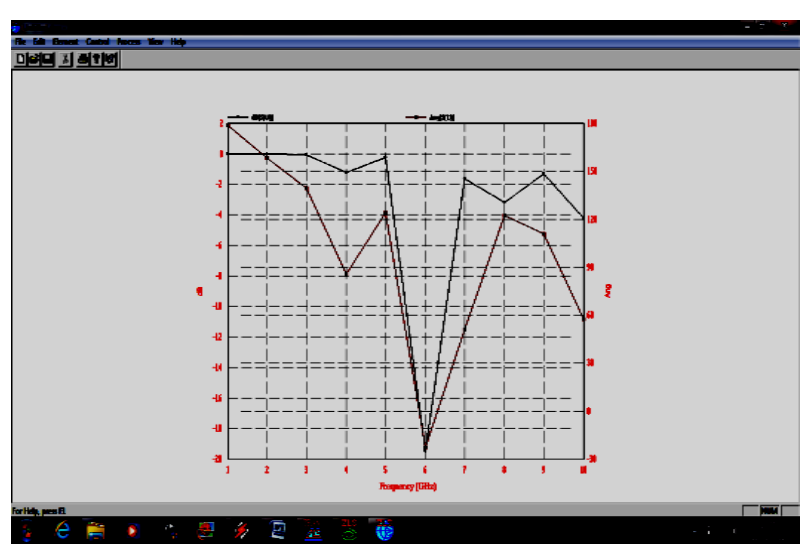

(b) For Triangular Geometry

At frequency of $10 \mathrm{GHz}$ the value of return loss is $-12.2 \mathrm{~dB}$.

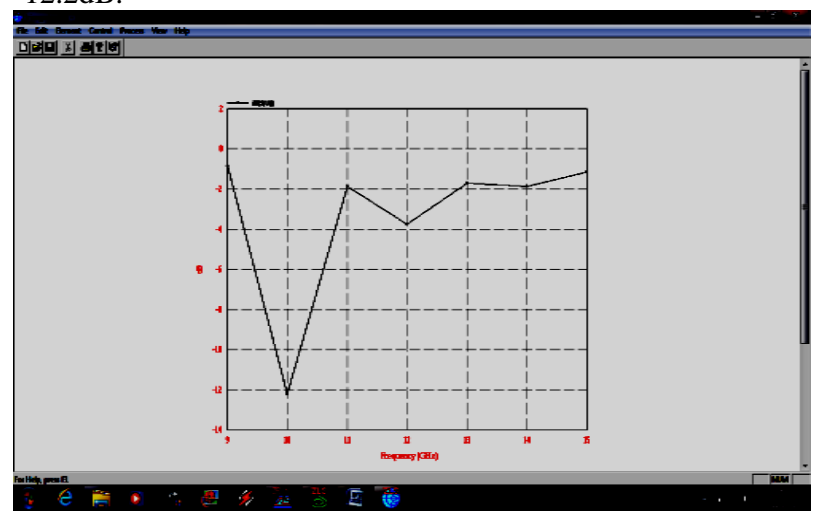

(c) For Circular Geometry

At frequency of $10 \mathrm{GHz}$ the value of return loss is $-15.5 \mathrm{~dB}$.

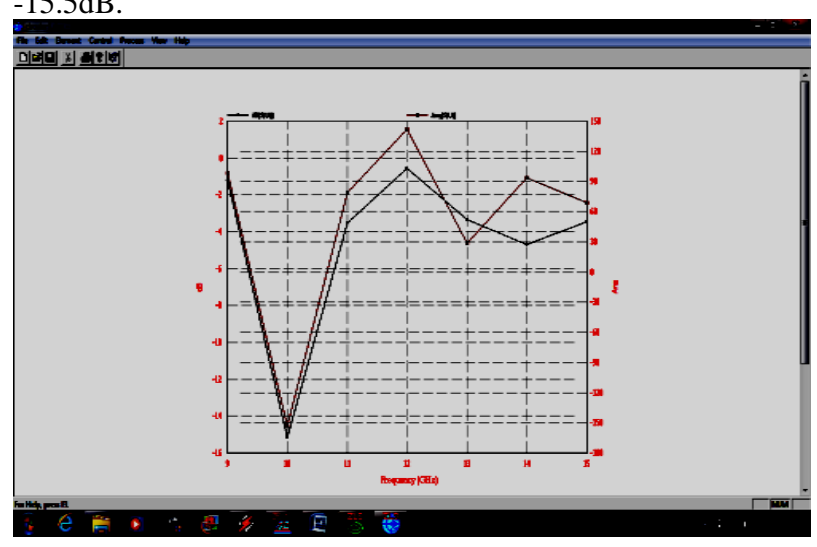

(3) S PARAMETER (magnitude in $\mathrm{dB}$ and phase) VS FREQUENCY IN GHz

(a) For Rectangular Geometry

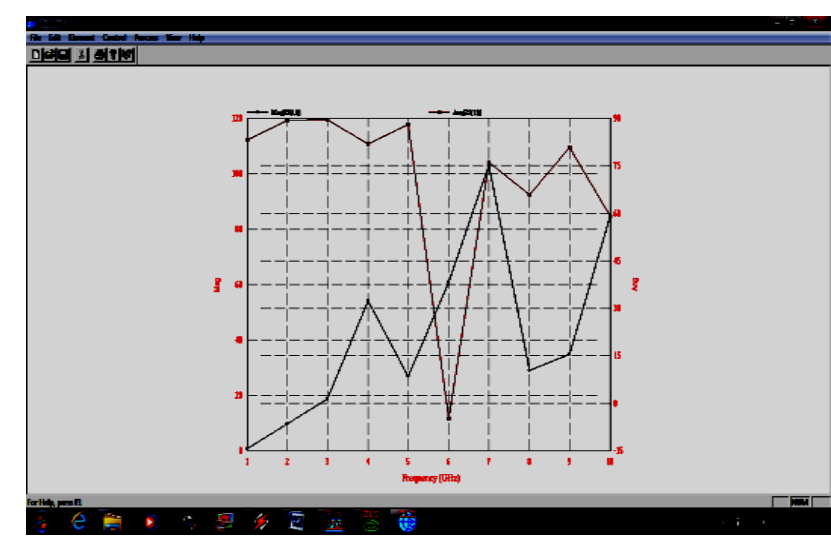

(b) For Triangular Geometry

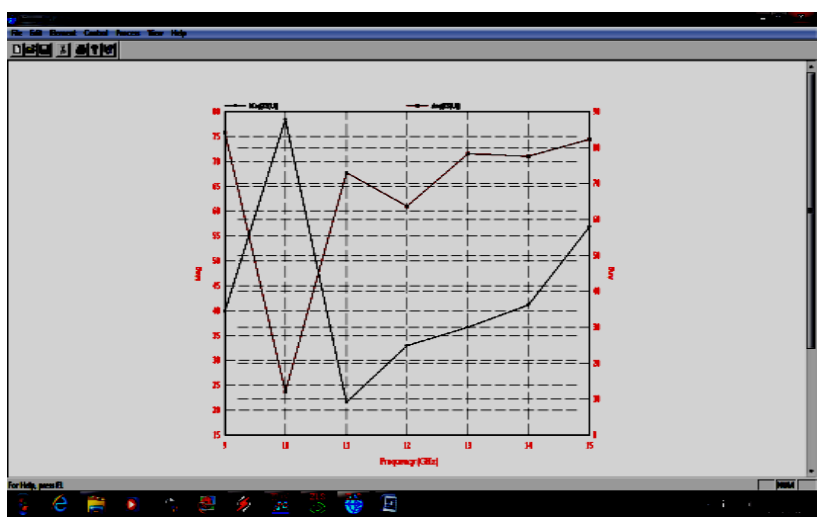

(c) For Circular Geometry

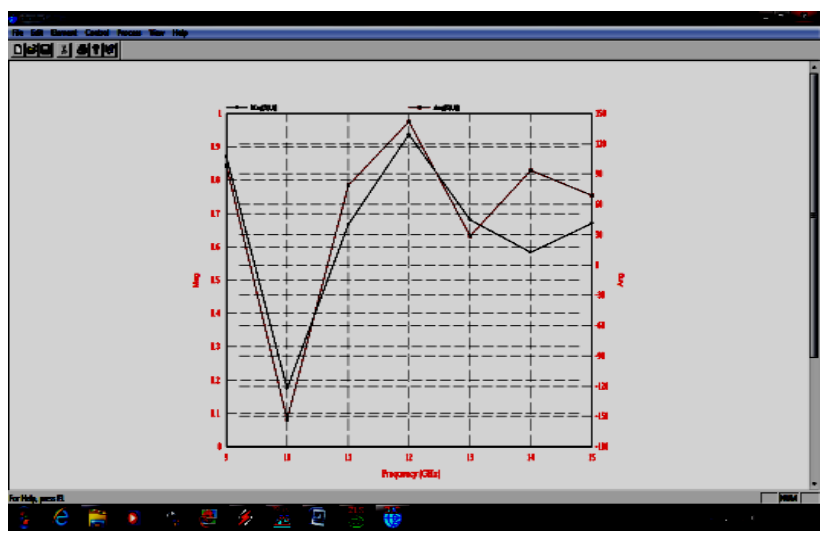

(3) SMITH CHART FOR DIFFERENT MEASUREMENT

(a) For Rectangular Geometry 


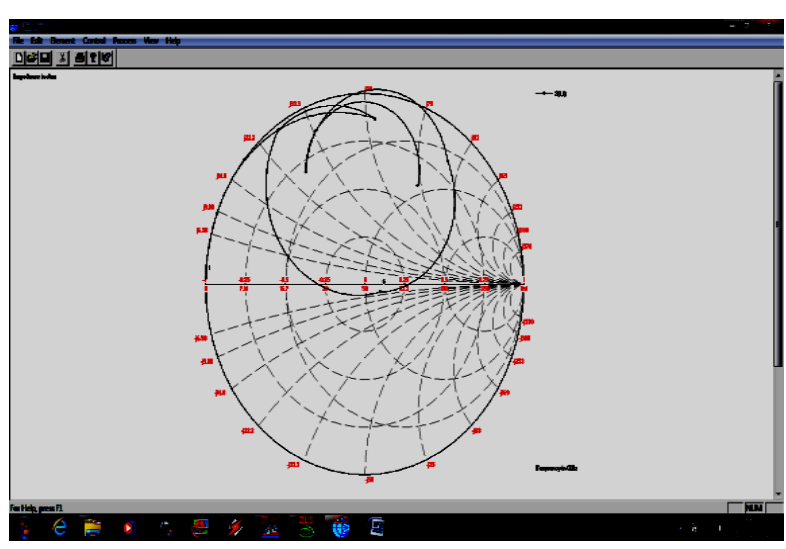

(b) For Triangular Geometry

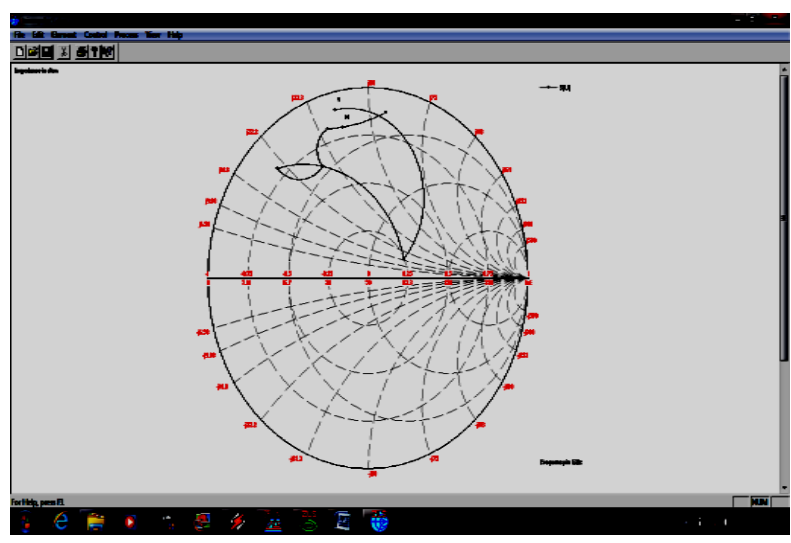

(c) For Circular Geometry

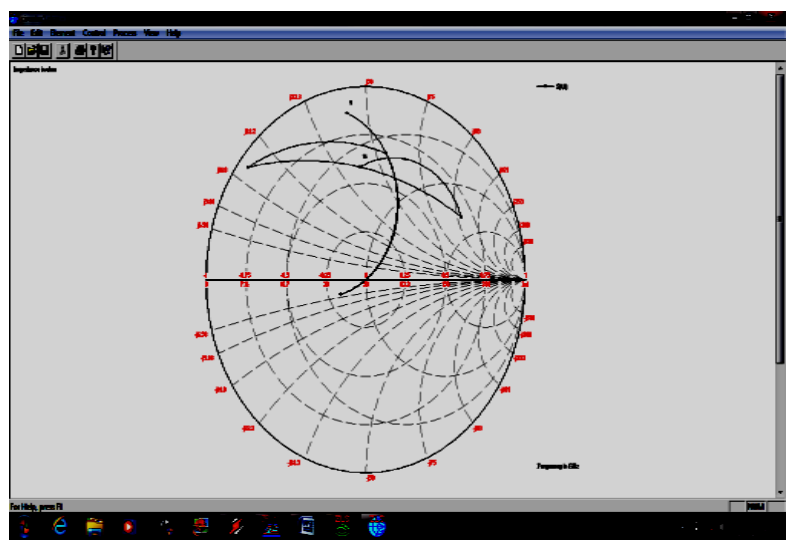

SIMULATION TABLE:-

\section{(a) For Rectangular Geometry}

\begin{tabular}{|l|l|l|}
\hline S.No & Co-ordinates & Result in dB \\
\hline 1 & $(0,0)$ & $-17 \mathrm{~dB}$ \\
\hline 2 & $(15,10.5)$ & $-20.5 \mathrm{~dB}$ \\
\hline 3 & $(15,0)$ & $-18 \mathrm{~dB}$ \\
\hline
\end{tabular}

\begin{tabular}{|l|l|l|}
\hline 4 & $(15,-10.5)$ & $-20 \mathrm{~dB}$ \\
\hline 5 & $(\mathbf{0},-\mathbf{1 0 . 5})$ & $-22 \mathrm{~dB}$ at $\mathbf{6 ~ G H z}$ \\
\hline 6 & $(-15,-10.5)$ & $-21 \mathrm{~dB}$ \\
\hline 7 & $(-15,0)$ & $-18 \mathrm{~dB}$ \\
\hline 8 & $(-15,10.5)$ & $-20 \mathrm{~dB}$ \\
\hline 9 & $(\mathbf{0}, \mathbf{1 0 . 5})$ & $\mathbf{- 2 2 d B}$ \\
\hline 10 & $(0,5.25)$ & $-16 \mathrm{~dB}$ \\
\hline 11 & $(7.5,0)$ & $-17 \mathrm{~dB}$ \\
\hline 12 & $(0,-5.25)$ & $-16 \mathrm{~dB}$ \\
\hline 13 & $(-7.5,0)$ & $-17 \mathrm{~dB}$ \\
\hline 14 & $(7.5,5.25)$ & $-5.5 \mathrm{~dB}$ \\
\hline 15 & $(7.5,-5.25)$ & $-5.5 \mathrm{~dB}$ \\
\hline
\end{tabular}

(b) For Triangular Geometry

\begin{tabular}{|l|l|l|}
\hline S.No & Co-ordinates & Result \\
\hline 1. & $(0,0)$ & $-7.1 \mathrm{~dB}$ \\
\hline 2. & $(15,0)$ & $-7.2 \mathrm{~dB}$ \\
\hline 3. & $(30,0)$ & $-7.1 \mathrm{~dB}$ \\
\hline 4. & $(22.5,12.99)$ & $-7.5 \mathrm{~dB}$ \\
\hline 5. & $(15,25.98)$ & $-7.1 \mathrm{~dB}$ \\
\hline 6. & $(7.5,12.99)$ & $-7.6 \mathrm{~dB}$ \\
\hline 7. & $(15,12.99)$ & $-6.5 \mathrm{~dB}$ \\
\hline 8. & $(7.55,6.6)$ & $-12.2 \mathrm{~dB}$ at $10 \mathrm{GHz}$ \\
\hline 9. & $(22.5,6.6)$ & $-11.99 \mathrm{~dB}$ \\
\hline 10. & $(15,19.45)$ & $-6.0 \mathrm{~dB}$ \\
\hline 11. & $(11.2,13.05)$ & $-7.1 \mathrm{~dB}$ \\
\hline 13. & $(18.7,13.05)$ & \\
\hline & & \\
\hline & & \\
\hline & & \\
\hline & & \\
\hline & & \\
\hline & & \\
\hline & & \\
\hline & & \\
\hline & & \\
\hline & & \\
\hline & & \\
\hline & & \\
\hline & & \\
\hline & & \\
\hline & & \\
\hline & & \\
\hline & & \\
\hline & & \\
\hline & & \\
\hline
\end{tabular}




\section{(c) For Circular Geometry}

\begin{tabular}{|c|c|c|}
\hline S.No & Co-ordinates & Results \\
\hline 1. & $(0,0)$ & $-10 \mathrm{~dB}$ \\
\hline 2. & $(5.3,0)$ & $-8.5 \mathrm{~dB}$ \\
\hline 3. & $(10.6,0)$ & $-6.8 \mathrm{~dB}$ \\
\hline 4. & $(12.8,0)$ & $-6.0 \mathrm{~dB}$ \\
\hline 5. & $(15,0)$ & $-14 \mathrm{~dB}$ \\
\hline 6. & $(0,5.3)$ & $-14 \mathrm{~dB}$ \\
\hline 7. & $(0,10.6)$ & $-6.9 \mathrm{~dB}$ \\
\hline 8. & $(0,12.7)$ & $-10 \mathrm{~dB}$ \\
\hline 9. & $(0,15)$ & $-14.1 \mathrm{~dB}$ \\
\hline 10. & $(5.3,10.6)$ & $-10.2 \mathrm{~dB}$ \\
\hline 11. & $(5.7,13.9)$ & $-15.5 \mathrm{~dB}$ at $10 \mathrm{GHz}$ \\
\hline 12. & $(10.6,10.6)$ & $-14.9 \mathrm{~dB}$ \\
\hline 13. & $(13.9,5.7)$ & $-15.5 \mathrm{~dB}$ \\
\hline 14. & $(5.3,5.3)$ & $-9.0 \mathrm{~dB}$ \\
\hline 15. & $(-5.3,0)$ & $-8.9 \mathrm{~dB}$ \\
\hline 16. & $(-10.6,0)$ & $-6.8 \mathrm{~dB}$ \\
\hline
\end{tabular}

\section{CONCLUSION}

All the three geometries of patch antenna are investigated including the radome effect. Results are found to be best in case of rectangular patch antenna. However the feed positions which produce the remarkable results lie on edge of rectangular patch. In case of circular geometry we get the optimum result at diametrical opposite points. In case of triangular geometry the results are not as good as in case of both rectangular as well as circular patch. This suggests that if we implement these feed points in practical application, we can obtain optimized result.

\section{REFRENCES}

[1] Experimental Investigation of an Equilateral Triangular Microstrip Antenna with a Dielectric Radome. Manotosh Biswas and Debatosh Guha, Institute of Radio Physics and Electronics, University of Calcutta, Kolkata (India). International Conference on Microwave -08

[2] Analysis of triangular patch antenna including radome effects. H.R. Hassani and D. Mirshekar-Syahkal.

[3] Input impedance and resonance characterstics of superstrate-loaded triangular microstrip patch. M. Biswas and D.Guha.

[4] D. Guha and J.Y. Siddiqui, "Resonant frequency of circular microstrip antenna covered with dielectric superstrate, "IEEE Trans. Antennas Propagate., vol 51, no.7, pp.1649-1652, July 2003.

[5] Improved CAD Formulae to Calculate the Input Impedance of an Equilateral Triangular Microstrip Patch Including Radome Effect. Manotosh Biswas and Anirban Mandal. 2009 International Conference on emerging Trends in Electronics and Photonic Devices \& Systems (ELECTRO-2009).

[6] Input impedance and resonance characterstics of superstrate-loaded triangular microstrip patch. M. Biswas and D. Guha. IET Microwaves, Antennas \& Propogation.

[7] Scattering Reduction of a Microstrip Patch With An An In-plane Biased Ferrite Cover Layer. David Hung Y. Yang, Department of Electrical Engineering and Computer Science, University of Illinois at Chicago, IL 60607 and Jesse A. Castaneda, Phraxos R\&D Inc. 2716 Ocean Park Blvd. \#1020, Santa Monica CA 90405.

[8] New Multiband E-Shape Microstrip Patch Antenna On RT DUROID 5880 Substrate and RO4003 Substrate for Pervasive Wireless Communication. Dr. Anubhuti Khare, Rajesh Nema and Puran Gour. 